\section{Territorialidades latentes. Auto Unión DKW y Fiat en la construcción del corredor Santa Fe- Santo Tomé - Sauce Viejo}

- Estefanía Szupiany

Instituto de Humanidades y Ciencias Sociales del Litoral, Consejo Nacional de Investigaciones Científicas y Técnicas, Argentina.

Recibido: 22 de agosto de 2017. Aceptado: 10 de octubre de 2017.

\section{Resumen}

En el marco de las políticas desarrollistas impulsadas en la década de 1960 en Argentina, un creciente optimismo en torno a la industria automotriz se vinculaba con la radicación de importantes firmas internacionales. Entre ellas, los casos de la fábrica alemana Auto Unión AG y la firma italiana Fiat Concord SA, representan un punto de inflexión en el desarrollo económico, productivo y, principalmente, territorial del corredor Santa Fe-Santo Tomé-Sauce Viejo. La propuesta de este articulo consiste en la exploración material y simbólica de la territorialidad industrial relacionada con la producción automotriz, en tanto dinámica asociada a los procesos de expansión de la ciudad de Santa Fe y su área de influencia, insertando el caso de estudio en el marco de las reconceptualizaciones planteadas por el nuevo paradigma de los estudios de la movilidad y el giro cultural en las ciencias sociales. El análisis focaliza en el ciclo de auge y caída de la industria automotriz santafesina, entre los años 1959 y 1981, periodo en el que la antigua colonia rural de Sauce Viejo experimentó el inicio de un proceso de transformación hacia un territorio donde la mixtura de usos es hoy un rasgo característico.

\section{Latent Territorialities. Auto Union DKW and Fiat in the construction of the corridor Santa Fe - Santo Tomé - Sauce Viejo}

Palabras claves

Territorialidades Expansión Urbana Corredores Urbanos Industria Automotriz Sauce Viejo

Palavras-chave

Territorialidades Expansão urbana Corredor Urbano Indústria automotiva Sauce Viejo
Keywords

Territorialities Urban Expansion Urban Corridors Automotive Industry Sauce Viejo 
exploration of the industrial territoriality related to the automotive production as a dynamic associated with the expansion processes of Santa Fe city and its area of influence. We insert the case study in the framework of the reconceptualization proposed by the new paradigm of studies about mobility and cultural turn in the social sciences. The analysis focuses on the boom and fall cycle of the Santa Fe automotive industry between 1959 and 1981, when the old rural settlement of Sauce Viejo experienced the beginning of a process of transformation towards a territory where the mix of uses is today a characteristic feature.

\section{Introducción}

Entre los diversos patrones de crecimiento que experimentan las ciudades contemporáneas, la expansión de la mancha urbana a partir de vías circulatorias se ha convertido en una tendencia dominante. Promovida por la creciente motorización de la movilidad física a lo largo del siglo XX, esta linealidad de la forma urbana ha sido generalmente analizada en tanto producto resultante de los diferentes modos de desplazamiento que acontecen en las infraestructuras de conexión vehicular. Sin negar la fuerza impulsora de estos ejes y sus flujos de tránsito, se advierte que los actuales procesos de urbanización requieren aproximaciones que trasciendan estas lecturas reduccionistas, en pos de una comprensión de la dialéctica emergente entre ambos elementos: corredores viales y expansión urbana, traza y mancha, respectivamente. Entre los estudios que concurren en esta articulación, Miralles-Guasch (2002) focaliza en la relación ciudad y transporte, una relación que si bien hoy es indiscutible y compleja su estudio dependió durante mucho tiempo de simples relaciones causales. A fin de superar este análisis reduccionista, y en sintonía con lo desarrollado previamente por Offner (1993), Miralles-Guasch sostiene que la relación ciudad y transporte implica una profunda comprensión de las dinámicas territoriales en que se insertan los medios de transporte. Su análisis de ciudades como Barcelona, París y Milán, comparte aproximaciones epistemológicas y metodológicas con estudios que articulan ciudad y transporte en el ámbito nacional. Para el caso de la Región Metropolitana de Buenos Aires, surgieron análisis que relacionan modelos de urbanización y patrones de movilidad (Blanco, 2006, 2016), como así también estudios que asocian movilidad, transporte y acceso (Gutiérrez, 2010). En sintonía con estas aproximaciones conceptuales y metodológicas, el territorio de la expansión puede ser pensado más allá de la simple extensión de los usos urbanos y, por lo tanto, conformado por múltiples territorialidades superpuestas. Territorialidades de la expansión cuyos desplazamientos ya no son sólo trámites indispensables para alcanzar un destino, sino prácticas sociales generadoras de espacio urbano (Castro, Lois, Zusman, 2007:10). Examinar estas territorialidades a partir de sus patrones de movilidad introduce la problemática aquí abordada -la relación entre la expansión urbana y los corredores viales- en el marco de las reconceptualizaciones emergentes del giro cultural en las ciencias sociales y, particularmente, del nuevo paradigma en los estudios de la movilidad.

Realizada esta consideración general, cabe señalar que el presente escrito es el resultado preliminar de una investigación en curso, la cual se encuentra focalizada en la expansión urbana de la ciudad de Santa Fe, cuyo patrón de crecimiento responde a la prolongación de vías circulatorias en distintas direcciones, incluyendo en su extensión a las localidades vecinas de Monte Vera y Recreo al Norte; Santo Tomé y Sauce Viejo al Suroeste; San José del Rincón y Arroyo Leyes al Este. Asimismo, es posible indicar que el recorte que aquí se presenta reflexiona en torno a la territorialización de la actividad industrial sobre el corredor de expansión Santa Fe-Santo Tomé-Sauce Viejo, en adelante corredor SF-ST-SV, a partir de la historia de la producción automotriz. Contextualizando su inserción en el ámbito local, y en el marco de la territorialidad 


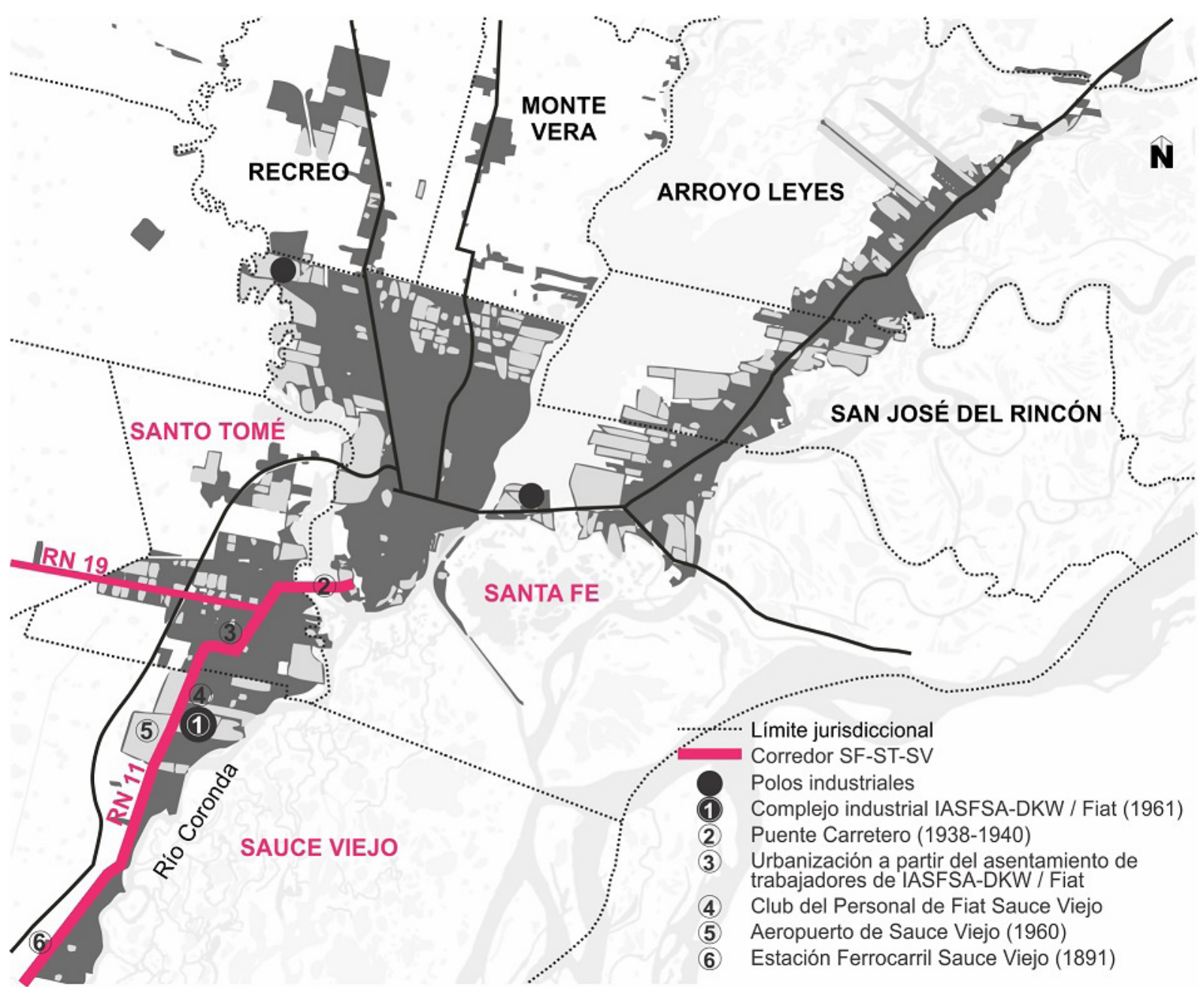

productiva de la expansión, el mismo adquiere cierta significatividad como eje de desarrollo del polo industrial Sauce Viejo-Santo Tomé sobre las Rutas Nacionales 11 y 19. Otros dos centros productivos se desarrollan en el área de expansión: hacia el Norte, el Distrito Industrial Los Polígonos próximo a la localidad de Recreo y conectado a la Avenida Circunvalación Oeste; y hacia el Este, el Parque Tecnológico Litoral Centro sobre la RN 168 (Figura 1). En cuanto a la inserción del corredor en el ámbito regional y nacional, puede decirse que su territorialización responde a la posición periférica de la ciudad de Santa Fe respecto al desarrollo del eje industrial La Plata-San Lorenzo o Frente Fluvial Pampeano.

Retomando el recorte propuesto, el período histórico comprendido en este estudio tiene su punto inicial en el año 1959 cuando se funda la Industria Automotriz Santa Fe SA y, seis meses más tarde, ésta se asocia con la firma alemana Auto Unión AG para fabricar los automóviles DKW. Tras un breve periodo de funcionamiento en una fábrica provisoria cercana al centro histórico de la ciudad de Santa Fe, en 1960 se inician los trabajos para la instalación de la planta principal en la localidad de Sauce Viejo, 12 km. al Suroeste de aquel centro, y emplazada frente al aeropuerto sobre el corredor de la Ruta Nacional 11. Luego de algunos años de creciente producción, la firma alemana decide retirarse en 1969, tras el impacto negativo de las medidas económicas impuestas por el gobierno de facto de Juan Carlos Onganía. No obstante, la industria automotriz continuó funcionando tras un convenio de colaboración celebrado entre Automotriz Santa Fe SA y Fiat Concord SA. Aprovechando las instalaciones construidas en Sauce Viejo por la Auto Unión AG, la Fiat inicia un significativo proceso de fabricación de
Figura 1. Caso de estudio en el área de expansión de la ciudad de Santa Fe (división por localidades) Fuente: elaboración propia a partir de datos extraídos del Servicio de Catastro e Información Territorial (S.C.I.T.) de la provincia de Santa Fe. 

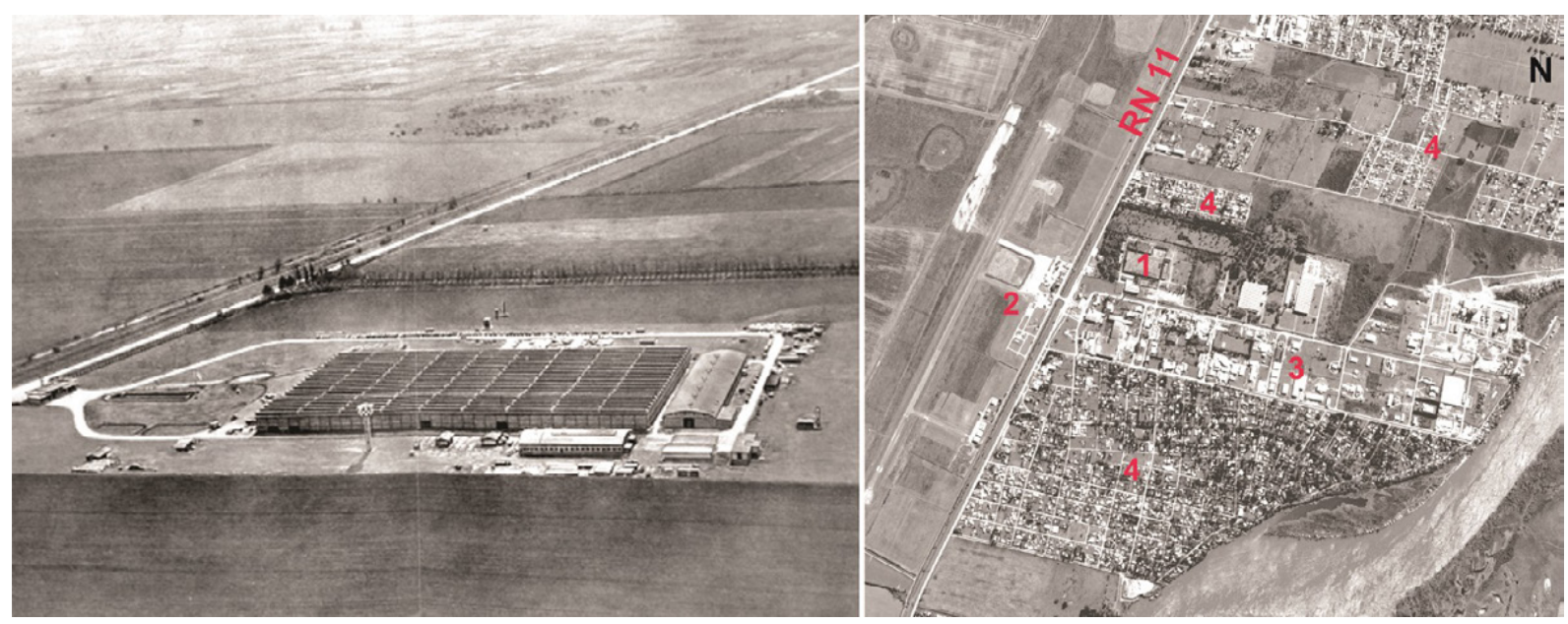

Figura 2. Transformación del tejido urbano en el corredor SF-ST-SV. Izquierda: Planta Industrial IASFSA-DKW en la década de 1960. Fuente: INDUSTRIA AUTOMOTRIZ SANTA FE S.A (1965) Memoria y balance general. Recuperado de https://www.flickr. com/photos/autounion1965part2/albums/72157629278662316. Derecha: Actual mixtura de usos urbanos (1) Planta Industrial IASFSA-DKW/ Fiat, en desuso; (2) Aeropuerto de Sauce Viejo; (3) Parque Industrial; (4) Loteos y barrios suburbanos. Fuente: elaboración propia a partir de imagen satelital Google Earth.

tractores, camiones pesados y motores, con una incidencia relevante en la producción nacional. Hacia finales de la década del 70, los avatares de la política argentina indujeron a la Fiat a cerrar sus puertas en 1981, provocando el abandono de toda la industria automotriz. Este ciclo, que abarca dos décadas de incesante desarrollo, no sólo tuvo un impacto en la actividad industrial de la región y el país; la extensión de servicios urbanos favorecida por la instalación de plantas fabriles, junto a la calidad ambiental que ofrecía el paisaje costero a la vera del Río Coronda, marcaron el inicio de un proceso de transformación en la localidad de Sauce Viejo. Los cambios registrados demuestran el paso de una colonia rural a un territorio donde la mixtura de usos se convirtió en un rasgo característico, entre galpones, industrias, aviones, espacios verdes y casas de fin de semana (Figura 2). Rasgos emblemáticos que han encontrado su lugar en el propio escudo de la Comuna de la localidad (Figura 3).

Con el objetivo de explorar la dimensión material y simbólica de la territorialidad industrial en los procesos de expansión de la ciudad de Santa Fe, el presente escrito inserta el corredor SF-ST-SV en el marco de las reconceptualizaciones planteadas por 
el nuevo paradigma de los estudios de la movilidad y el giro cultural en las ciencias sociales. A continuación, se profundiza en el ciclo de la industria automotriz santafesina en Sauce Viejo a partir de su periodización presentada en tres apartados. En el primero de ellos, se examina el proceso de institucionalización de la obra vial en Argentina durante la década de 1930, y los orígenes del trazado de la RN11 sobre el que luego se extenderá el corredor SF-ST-SV. En segundo lugar, se analiza el auge de la industria automotriz en Santa Fe, particularmente, el surgimiento del complejo industrial para la fabricación de autos DKW en la localidad de Sauce Viejo durante la década del 60 y, posteriormente, se indaga en el funcionamiento de la Fiat entre 1969 y 1981, período caracterizado por un fuerte crecimiento de la productividad industrial y, al mismo tiempo, por una intensa conflictividad social que sucumbió en los años más sombríos de la historia argentina.

\section{Aportes conceptuales para el estudio de los corredores de expansión urbana}

\section{Explorando el territorio desde las territorialidades de la expansión}

El crecimiento de las ciudades ha sido tradicionalmente esbozado como el derrame de una mancha de aceite, fundamentalmente a partir de estudios urbanos de sesgo formalista. Un modo de aproximación al territorio que hoy resulta insuficiente para la comprensión de los procesos de expansión cuyo patrón de crecimiento responde a la extensión de vías circulatorias. Si se analiza la conformación del corredor SF-ST-SV, se evidencia un eje fuertemente segmentado a nivel espacial y construido a partir de dinámicas fragmentadas. Los orígenes de tal discontinuidad se remontan al año 1891, momento que comienza a funcionar la estación de trenes sobre la traza del Ferrocarril Belgrano Santa Fe-Rosario, impulsando la creación del pueblo de Sauce Viejo. Tras la apertura y posterior pavimentación de un camino inicialmente subsidiario y paralelo a las vías férreas -actual RN11-, el territorio sauceño experimentó una serie de transformaciones vinculadas a las características de su localización. Por un lado, la expansión de la actividad industrial de la ciudad de Santa Fe, emplazada estratégicamente sobre las Rutas Nacionales 11 y 19; por otro, la expansión de la vida urbana que, en armonía con el paisaje costero a la vera del Río Coronda, se consolidó inicialmente a partir de la construcción de casas de fines de semana y, más tarde, con la formación de barrios de vivienda permanente. La territorialización de ambas dinámicas derivó en la conformación de un corredor estrictamente zonificado. Ahora bien, en tanto resultado del crecimiento demográfico ${ }^{1}$, el aumento de los movimientos pendulares diarios $y$, por consiguiente, de la movilidad cotidiana urbana, invitan a repensar el rol que asume la movilidad en la transformación de la forma urbana, y el modo en que el corredor es percibido, concebido y vivido a lo largo de su extensión, aludiendo a la trialéctica de la espacialidad desarrollada por Soja (1999).

Influenciado por la obra de Henri Lefebvre, Soja defiende un modo alternativo de investigación espacial que supere el dualismo omnipresente o lógica binaria entre el Primer Espacio y Segundo Espacio - espacio percibido y concebido, respectivamente-, incorporando un Tercer Espacio -espacio vivido-, un espacio posible de ser resignificado y activado por medio de la acción e imaginación social. Esta clasificación puede alinearse con las reconceptualizaciones surgidas en torno a la idea de territorio, particularmente aquella desarrollada por Haesbaert (2011) quién lo entiende a partir de una perspectiva que integra tanto las visiones materialistas como idealistas. Ante la enorme polisemia en la conceptualización de territorio y territorialidad, Haesbaert insiste en la importancia de aclarar sus principales líneas teórico-conceptuales. Si bien el autor reconoce cuatro vertientes básicas en las que se agrupan las diferentes nociones
1. Según el Censo Nacional de Población, Hogares y Viviendas correspondiente a los años 1991, 2001 y 2010, la localidad de Sauce Viejo registró un aumento poblacional de $3.391,6.825$ y 8.123 habitantes, respectivamente; al tiempo que la ciudad de Santo Tomé registró, para el mismo período, un crecimiento demográfico entre $44.533,59.072$ y 66.133 habitantes. 
de territorio -política, cultural, económica y natural-, propone organizar su conceptuación a partir de la fundamentación filosófica de cada abordaje y en relación a los binomios materialismo-idealismo y espacio-tiempo. Así, identifica las perspectivas materialistas -aquellas que se reducen a concepciones naturalistas, de base económica, o de la tradición jurídico-política-, y las perspectivas idealistas -aquellas que suponen una dimensión ideal ligada al carácter subjetivo del territorio y donde el concepto de territorialidad emerge en el debate para resaltar las cuestiones de orden simbólico y cultural-. Por lo tanto, el territorio concebido por el idealismo no es simplemente una entidad exterior a la sociedad que lo habita; es un territorio cultural que posee identidad y valores éticos, espirituales, simbólicos y afectivos.

Pero es desde un enfoque integrador de las concepciones materialistas e idealistas donde Haesbaert defiende una lectura contemporánea del territorio. Un territorio que ya no es experimentado en su totalidad sino de manera integrada, experiencia que, según el autor, solo es posible si estamos articulados en red a través de múltiples escalas. Superando la lógica de los territorios-zona que no admiten superposiciones, Haesbaert (2011:68) define los territorios-red como aquellos "...discontinuos a nivel espacial pero conectados y articulados entre sí de modo intenso"; y destaca como telón de fondo una concepción híbrida del espacio, donde materialidad e idealidad se relacionan en una compleja interacción espacio temporal. A partir de esta noción hibrida, Haesbaert elabora una perspectiva que, fundada bajo el predominio del componente red, supone la activación de múltiples territorialidades. Por su parte, Massey (2005) contribuyó a la politización de ese espacio a través de tres proposiciones: el reconocimiento del espacio como el producto de interrelaciones e interacciones; el espacio como la esfera donde coexisten múltiples trayectorias; y el espacio en tanto proceso de construcción constante. Estas concepciones de espacio y territorio sumadas a la idea del Tercer Espacio o espacio vivido (Soja, 1999), sustentan un conjunto de propuestas para superar los dualismo dominantes entre materialismo-idealismo, objetividadsubjetividad, Primer Espacio-Segundo Espacio. Los orígenes de esta ruptura radical con el dualismo limitante, sostiene Soja, debe rastrearse en los trabajos de Michel Foucault y Henri Lefebvre quienes defienden que siempre hay un "...Otro término, una tercera posibilidad destinada a vencer la lógica categóricamente cerrada del uno u otro en favor de una lógica diferente, más flexible y expansiva del a la vez y también" (Soja, 1999:192). Este enfoque integrador se torna indispensable para comprender los corredores de expansión urbana, si se piensa en ellos en tanto híbridos espaciales que no encuentran lugar en la dualidad urbano-rural. No son rurales ni urbanos, no pertenecen al campo pero tampoco a la ciudad. La conflictividad inherente a estos espacios y la coexistencia de dinámicas incompatibles y opuestas, están estrechamente relacionadas con la indefinición tipológica de sus ejes estructurantes, indeterminación que oscila entre las características de una vía urbana y de una vía rápida. Concebidas en su origen como infraestructura vial a nivel inter-urbano y/o territorial, muchas rutas y autopistas fueron alcanzadas y contenidas por los procesos de expansión de las ciudades. Lejos de ser redefinidas en términos urbanos y, por lo tanto, reconfiguradas como calles o avenidas, estas vías se mantuvieron conforme a las particularidades de las altas velocidades, al transporte de carga, y a la exclusión del tránsito peatonal.

Con el objetivo de examinar los corredores en el marco de esta redefinición de los conceptos de espacio y territorio, se propone aquí la noción de territorialidades de la expansión en tanto premisa teórica para abordar el estudio de una expansión urbana compleja y diferencial. Noción que supone la comprensión del territorio en red y construido por múltiples territorialidades, discontinuas a nivel espacial pero articuladas por dinámicas funcionales y apropiaciones simbólicas. Estas redes dinámicas impulsadas por la extensión de funciones urbanas, responden fundamentalmente a lógicas de tipo productivo, residencial y recreativo/turístico, cuyos patrones de asentamiento y movilidad resultan, muchas veces, incompatibles y/o conflictivos entre ellos. Identificar 
estas redes funcionales y simbólicas supone una aproximación metodológica enfocada en las redes más que en zonas, evitando así recortes geográficos defendidos por las perspectivas materialistas. Entre estas territorialidades de la expansión, la territorialidad industrial que aquí se indaga en torno a la producción automotriz representa una de las múltiples trayectorias que coexisten en el territorio red de la expansión urbana. Una territorialidad aparentemente inactiva desde la década del ochenta, pero aún latente en la caracterización industrial del corredor SF-ST-SV.

\section{Territorialidades de la expansión en el marco del nuevo paradigma de la movilidad}

Bajo esta contextualización, el presente estudio propone insertarse en el marco de la perspectiva contemporánea centrada en el nuevo paradigma de los estudios de la movilidad. Superando análisis reduccionistas que asimilan transporte y movilidad, este enfoque entiende "el desplazamiento como una práctica social y no sólo como ese trámite indispensable para alcanzar un destino" (Castro, Lois, Zusman, 2007:10); "como una práctica social de desplazamiento en el territorio que conjuga deseos y necesidades de desplazamiento" (Gutiérrez, 2012:67). Sheller y Urry (2006) sostienen que la movilidad hoy desafía a las ciencias sociales a replantear tanto sus objetos como metodologías de investigación, problematizando dos conjuntos de teorías existentes. Por un lado, las teorías sedentarias han resultado insuficientes para examinar el impacto de la automovilidad en la transformación espacio-temporal del habitante moderno urbano y suburbano. En tanto que las teorías nómades han focalizado en los procesos de desterritorialización y en el fin de los Estados nacionales como contenedores de sociedades. Por su parte, los autores manifiestan que el nuevo paradigma de la movilidad supone un contexto en el que operan, simultáneamente, ambos relatos, reconociendo la existencia de una interacción compleja entre viajar y habitar. Si los estudios tradicionales del transporte distinguen el viaje de las actividades, este mobility turn entiende que las actividades pueden ocurrir también en movimiento, al tiempo que la distinción entre lugares y viajantes es también superada si se comprende que los mismos lugares pueden ser creados a partir de las actividades y el movimiento. Este cambio en el modo de abordar los estudios urbanos, permite comprender los corredores viales de la expansión urbana en tanto sistemas híbridos de materialidades y movilidades, donde el atravesamiento de lugares aparentemente singulares se convierte en una interacción compleja.

En relación a esta nueva conceptualización de la movilidad, Crawford (2014) plantea redefinir la idea de espacio público y propone llamar a esta construcción "el espacio cotidiano", retomando la crítica de la vida cotidiana desarrollada de Henri Lefebvre. Es el espacio que aloja la vida cotidiana, aquel lugar común y mundano donde el individuo interactúa con la ciudad. Es el paisaje genérico que aloja el automóvil, manifiesta Crawford, el espacio trivial de las carreteras, las calles, las autopistas, donde la movilidad es el elemento definitorio. Una movilidad que muchas veces se convierte en revueltas y redefine el espacio en tanto lugar de protesta, ira y expresión pública. La identidad de estos espacios cotidianos, por lo tanto, no es fija e inmutable. Más que una función específica, adquiere significados múltiples y cambiantes de acuerdo a las actividades transitorias que allí se desarrollan con los ritmos de la vida diaria. Esta reconceptualización del carácter público de los espacios es retomada aquí con el fin de comprender la cotidianeidad emergente en las territorialidades de la expansión; en particular, en la creación de espacios de identidad relacionados con la territorialización de la industria automotriz santafesina: un segmento del corredor cuya memoria es reactivada y resignificada a partir del aumento progresivo de la movilidad cotidiana.

Parte del complejo industrial de Sauce Viejo hoy se encuentra abandonado desde que la Fiat anunciara su deceso; sin embargo, los restos de una fábrica tan importante en la historia desarrollista regional parecen revivir ante una movilidad cada vez más 
cotidiana. Una movilidad creadora de espacio, de lugares y de memoria, impulsada por el crecimiento demográfico registrado en el corredor SF-ST-SV en las últimas décadas. El estudio de este ciclo tan particular en la historia del corredor, tiene entre sus antecedentes el trabajo presentado por Moraglio (2007) quién, en relación a la autopista Turín-Savoya, sostiene la existencia de una historia única y propia para cada corredor, en el marco de una historia del sistema de autopistas altamente fragmentada en Italia.

\section{El ciclo de la industria automotriz santafesina en Sauce Viejo}

\section{Institucionalización del camino argentino: la Ruta Nacional 11 y los orígenes del corredor Santa Fe-Santo Tomé-Sauce Viejo}

La producción automotriz santafesina representa un capítulo central en la historia de la traza de la RN11 sobre el tramo de expansión de la ciudad de Santa Fe hacia el Sur. Desde sus orígenes en la década de 1920 este camino, de comunicación regional en sus inicios y más tarde nacional, estuvo vinculado a la apertura de caminos paralelos a las vías férreas, acción proyectada con el objetivo de incluir determinadas regiones aisladas $y$, fundamentalmente, como alternativa al costoso sistema de transporte ferroviario. Esta lucha del camino contra el riel, tal como lo pronunciara en el año 1922 el Gobernador de la Provincia de Santa Fe Dr. Enrique Mosca en la inauguración de las Sesiones Ordinarias de la Legislatura Provincial, dio lugar a una nueva política vial que definió la estructura territorial contemporánea. Al mismo tiempo, se asistía de manera incipiente en el ámbito local a un incremento del parque automotor y a nuevas pautas culturales en relación al objeto automovilístico (Ballent, 2005:110-113). Inicialmente consolidados como caminos de tierra, no es sino hasta la aprobación de la Ley 2.157 del año 1927 que se autoriza la pavimentación de caminos en la Provincia, entre ellos los tramos Rosario-Santa Fe y Santa Fe-San Justo. Crónicas de la época denotan las aspiraciones que impulsaron la creación de Comisiones de Estudio para la concreción de ambos tramos:

Que es indudable, por otra parte, la necesidad de iniciar la ejecución de dichas obras, por cuanto con ellas se beneficiarán extensas zonas agrícolas y comerciales, ofreciendo un amplio campo al desarrollo progresivo de diversas industrias rurales, desde que ellas implican la seguridad del transporte económico y permanente a los mercados del consumo, lo que trasuntará en beneficio de los pueblos (El Orden, 11/10/1928).

Ambas secciones conformarán luego una extensión importante del trazado de la RN 11, denominada así a partir de la incorporación de la Provincia al Plan Vial Nacional en 1932. En ese mismo año se inicia la pavimentación del tramo Rosario-Santa Fe y se concluye diez años más tarde en 1942, período durante el cual se construye en uno de sus extremos el Puente Carretero sobre el río Salado. Esta obra de singular importancia para el ámbito local, fue ejecutada entre los años 1938 y 1940 y vinculó las ciudades de Santa Fe y Santo Tomé dando un impulso renovado al desarrollo urbano de ambas localidades y, consecuentemente, a la localidad de Sauce Viejo. Otra de las obras emprendidas en este periodo y relacionada con el caso de estudio, es el trazado de la RN19 desde su intersección con la RN11 en Santo Tomé hasta la localidad de San Francisco en la Provincia de Córdoba. Dada la conectividad que ofrecían ambas rutas entre la ciudad de Santa Fe con las ciudades de Rosario y Córdoba, dos de los centros productivos más importantes del país, el proceso de urbanización sobre ambos ejes quedará supeditado a esta particular situación locacional.

Este proceso de consolidación de caminos regionales en la década de 1930, asume cierta significatividad en el marco de la formación institucional en torno a la obra vial. La sanción de la Ley Nacional de Vialidad no 11.658 y la creación de la Dirección Nacional 
de Vialidad como organismo autónomo en 1932, emergieron en un contexto alentador alrededor de la red caminera. Ballent (2005) indaga más allá de éste proceso de institucionalización, y examina diversos aspectos de la construcción de representaciones en torno a la red vial durante la década de 1930. La autora se refiere a una "epopeya del estado moderno" para calificar el nutrido imaginario que motivó la red caminera no sólo en los niveles gubernamentales sino también en distintos sectores de la sociedad. Entre los objetivos de la mencionada Ley, la planificación de un sistema troncal de caminos estaría dirigido, preferencialmente, a la construcción de caminos radiales a los puertos, a los accesos a las estaciones ferroviarias, a los caminos que unen las provincias y los territorios nacionales, a los accesos a países limítrofes, y a los caminos que intercomuniquen las ciudades importantes con los centros de producción. Por su parte, las propuestas provinciales se sumaron a este proyecto nacional. La Provincia de Santa Fe adhiere al sistema nacional mediante la Ley 2.303 y, luego de algunas décadas de afianzamiento estatal, en 1958 nace la Dirección Provincial de Vialidad, constituida como organismo descentralizado con carácter autárquico a partir de la Ley Orgánica nº 4.908 (Dirección Provincial de Vialidad, 1988). El análisis y caracterización de esta creciente institucionalización de las vialidades nacional y provincial, resulta esclarecedor para la comprensión de los procesos de urbanización escindidos de la planificación tecnocrática en la que se consolidó el crecimiento de los centros urbanos argentinos.

\section{El proyecto industrial automotriz en el proceso de expansión de la ciudad de Santa Fe: el caso de Industria Automotriz Santa Fe S.A. - Fábrica argentina de vehículos DKW Auto Unión (1959-1969)}

El posicionamiento estratégico del territorio aledaño a la intersección de las Rutas Nacionales 11 y 19, se convirtió paulatinamente en un enclave oportuno para la localización de proyectos regionales. Entre las primeras iniciativas, la localización del Aeropuerto en la localidad de Sauce Viejo, próxima al límite jurisdiccional con la ciudad de Santo Tomé, sentó las bases de un proceso de expansión de alcance territorial. Tras una aspiración mantenida durante muchos años para dotar a la ciudad de Santa Fe de comunicaciones aéreas (El Litoral, 14/04/1935; El Orden, 12/10/1949), en 1950 se inician las gestiones para trasladar las instalaciones del Aero Club Santa Fe a su actual emplazamiento (El Orden, 29/11/1950), y en 1955 queda inaugurado el servicio aéreo de pasajeros de Aerolíneas Argentinas (El Litoral, 09/12/1955). Emplazamientos posteriores dieron lugar a la instalación de plantas industriales de escala internacional, delineando la impronta productiva que distinguió al corredor SF-ST-SV respecto de los corredores de crecimiento insertos en el área de expansión general. Así, la instalación de la industria Automotriz Santa Fe DKW Auto Unión y la planta de la Tool Research Argentina en 1960, inauguran un periodo de industrialización sin precedentes en el ámbito local. Cabe destacar, que a la localización oportuna de la ciudad de Santa Fe equidistante de los dos centros productivos más importantes del país en aquellos años -Córdoba y Buenos Aires-, se sumaron otros factores de singular importancia para la radicación de complejos industriales. Entre ellos, la capacidad energética de la ciudad y su área de influencia; y la existencia de técnicos especializados formados en la Universidad Nacional del Litoral a través de la Escuela Industrial Superior y la Facultad de Ingeniería Química.

En medio de una ciudadanía entusiasta Arturo Frondizi asume la presidencia en 1958. La ilusión generalizada radicaba en la promesa de sacar al país de su estancamiento y atraso, a partir de un audaz programa de modernización y desarrollo en sintonía con las políticas de Industrialización por Sustitución de Importaciones -ISI- adoptadas con anterioridad en el país. Sin profundizar en los conflictos políticos emergentes en el intento por superar la dicotomía peronismo-antiperonismo, interesan aquí las repercusiones que en el plano económico y territorial derivaron las políticas desarrolistas. Las condiciones favorables que éstas ofrecían atrajeron inversiones extranjeras, 
cuyos capitales incrementaron la capacidad productiva e industrial y fomentaron la instalación de plantas modernas en las principales ciudades. Entre las industrias de mayor crecimiento a nivel nacional, la producción de automóviles, acero y combustibles recibieron un gran impulso (Novaro, 2010:39-63). El sector automotriz se convirtió en prioridad del plan modernizador, manifestada en el Régimen de Promoción de la Industria Automotriz según decreto no 3.693/59 del Poder Ejecutivo Nacional, dirigido fundamentalmente a incrementar la producción nacional y con el objetivo de fabricar la totalidad de las unidades en el país. La Provincia de Santa Fe, bajo el mandato del Gobernador Carlos Sylvestre Begnis, adhiere a las políticas desarrollistas transformando su producción en términos cuantitativos y cualitativos (Vicentín, 2013). En el marco de dicho decreto nace IASFSA - Industrias Automotriz Santa Fe SA- y algunos meses después se asocia a la firma alemana Auto Unión AG para la fabricación de los automóviles DKW, pasándose a denominar Industria Automotriz Santa Fe S.A. Fábrica argentina de vehículos DKW Auto Unión. El comienzo de la actividad conjunta quedó inaugurado con la llegada del primer cargamento proveniente de Alemania, con partes de vehículos y elementos necesarios para la puesta en funcionamiento de la fábrica que funcionó, provisionalmente, en el centro de la ciudad de Santa Fe ( $E l$ Litoral, 25/01/1960). Días después, en un acto celebrado en la Casa de Gobierno, se exhibieron las primeras tres unidades piloteadas por el reconocido campeón mundial de automovilismo Juan Manuel Fangio (El Litoral, 03/02/1960). Durante la ceremonia, el Ing. Huerta, presidente del directorio de la DKW, destacó que el proceso industrial de la empresa se integraría con la instalación de industrias subsidiarias, en sintonía con los objetivos propuestos en el Régimen de Promoción de la Industria Automotriz. Esta voluntad expansiva se verifica en el territorio santafesino con la formación de la Tool Research Argentina SA, una fábrica de capitales norteamericanos para la fabricación de engranajes, bulonería milimétrica, vidrios irrompibles -sandwichglass- y sección galvanoplastia. Previendo la futura localización de la Industria Automotriz Santa Fe S.A. - Fábrica argentina de vehículos DKW Auto Unión, la firma norteamericana construye su planta industrial sobre la RN11 en la localidad de Sauce Viejo (El Litoral, 08/10/1960).

Iniciados los trabajos para la construcción de la planta industrial IASFSA-DKW en Sauce Viejo, el Ing. Huerta deja asentado el optimismo emergente en el ámbito local en torno al objeto automovilístico:

Un conjunto de voluntades argentinas con la mente fija en hacer algo más que nuestra patria, decidió iniciar en este país una actividad industrial que cumplimentando nuestra economía posibilitara al hombre su mejor actividad, asegurando su movilidad.

Y al decidirse por la industria automotriz no han medido sólo el aspecto económico y el enorme desarrollo técnico que en todos los aspectos ella trae aparejado: han tenido presente también el bienestar que se crea por la transformación psicológica que se opera en los pueblos bien motorizados (El Litoral, 22/03/1960).

Tras un año y medio de funcionamiento en la fábrica provisoria, la producción se traslada definitivamente a su planta de montaje en la localidad de Sauce Viejo, emplazada en un predio de aproximadamente 100.000 metros cuadrados sobre la RN11 y frente al Aeropuerto (Figura 4). Crónicas de la época pronosticaron la fuerza impulsora de la nueva planta industrial en el proceso de expansión urbana de la ciudad de Santa Fe en "la hasta ayer verde campiña":

No será sino con un pequeño dejo de nostalgia que los santafesinos veremos cómo vuelve a reinar el silencio en la popular esquina del Auto Unión de 25 de Mayo y Salta. Pero esa pequeña nostalgia cederá muy pronto al comprobar que esa ida 


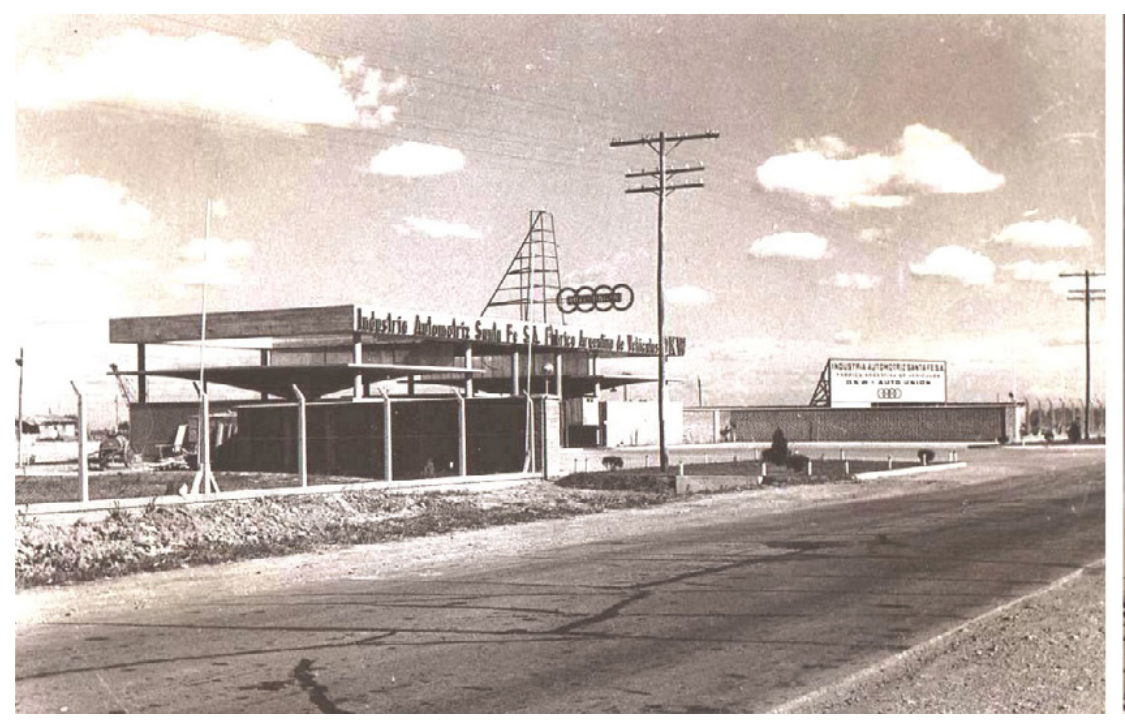

posibilitará la expansión de la ciudad hacia los distritos vecinos, al punto tal, que no es aventurado predecir que dentro de pocos años, el complejo conurbano "Gran Santa Fe" comenzará precisamente allí donde las luces de neón anuncian el asiento de Industria Automotriz Santa Fe, la cuna de la versión del "vehículo automóvil de vapor”, de “el deseo del niño”, de “la pequeña maravilla” (El Litoral, o2/og/1961)

Y a continuación, la misma crónica alude a la relación expansión - movilidad, una movilidad que puede ser entendida en tanto productora de espacio urbano:

Sí, no habrá nostalgias. No podrá haberlas porque el diario desplazamiento de los centenares de obreros y empleados, el afanoso ir y venir de decenas de vehículos, posibilitará el nacimiento de nuevas actividades junto a la ruta. Todo, desde el puente carretero hasta las últimas alambradas de la fábrica, se habrá transformado en algo así como en un apéndice urbano de la gran ciudad; de la ciudad que un 26 de enero de 1960 recibió en su puerto el primer envío que iba a ser la simiente generosa que iba a multiplicarse en esta realidad magnifica que hoy nos es dable contemplar (El Litoral, 02/og/1961).

Si se evalúa en términos comparativos la producción de IASFSA-DKW en Argentina, se evidencia que su participación en el conjunto del mercado automotriz no representó más del $4 \%$ de la producción nacional. Sin embargo, el éxito de esta empresa radicó en ser la única industria del mercado nacional en fabricar el modelo 1000S, perteneciente al más reducido de los segmentos con motores de entre 800 y $1.400 \mathrm{~cm}^{3}$ de cilindrada. La centralidad que asumió este modelo en la producción de IASFSA-DKW, se reflejó en el éxito de sus ventas y en una alta aceptación del público en general, al punto que la Revista Parabrisas (1964) en la publicación del test de evaluación manifiesta que "el Auto Unión 1000S es un señor auto" (Figura 5). De un total de 32.628 unidades fabricadas entre 1960 y 1969, 21.797 corresponden al modelo 1000S (Vicentín, 2013:21). A pesar de su baja productividad respecto de la industria automotriz nacional, la planta de Sauce Viejo mantuvo una intensa actividad a lo largo de la década del 60, llegando a emplear alrededor de 1.500 trabajadores de la región e impulsando la producción de un gran número de industrias subsidiarias. Sin embargo, la empresa debió enfrentarse a diversas dificultades económicas y de funcionamiento, lo que derivó en la paralización de las actividades en el año 1968. Ante el asombro del ámbito local y las preocupaciones lógicas de un cierre definitivo, los distintos sectores involucrados gestionaron un acuerdo con IMEMA, empresa subsidiaria de Fiat Concord, para el traspaso de la empresa y, por consiguiente, de la planta industrial de Sauce Viejo (El Litoral, 05/04/1969). Su
Figura 4. Imágenes de la nueva planta de Industria Automotriz Santa Fe S.A. - Fábrica argentina de vehículos DKW Auto Unión, en la localidad de Sauce Viejo sobre la RN11. Fuente: Recuperado de https://www.flickr.com/photos/autounion1965/albums/72157606595632693 


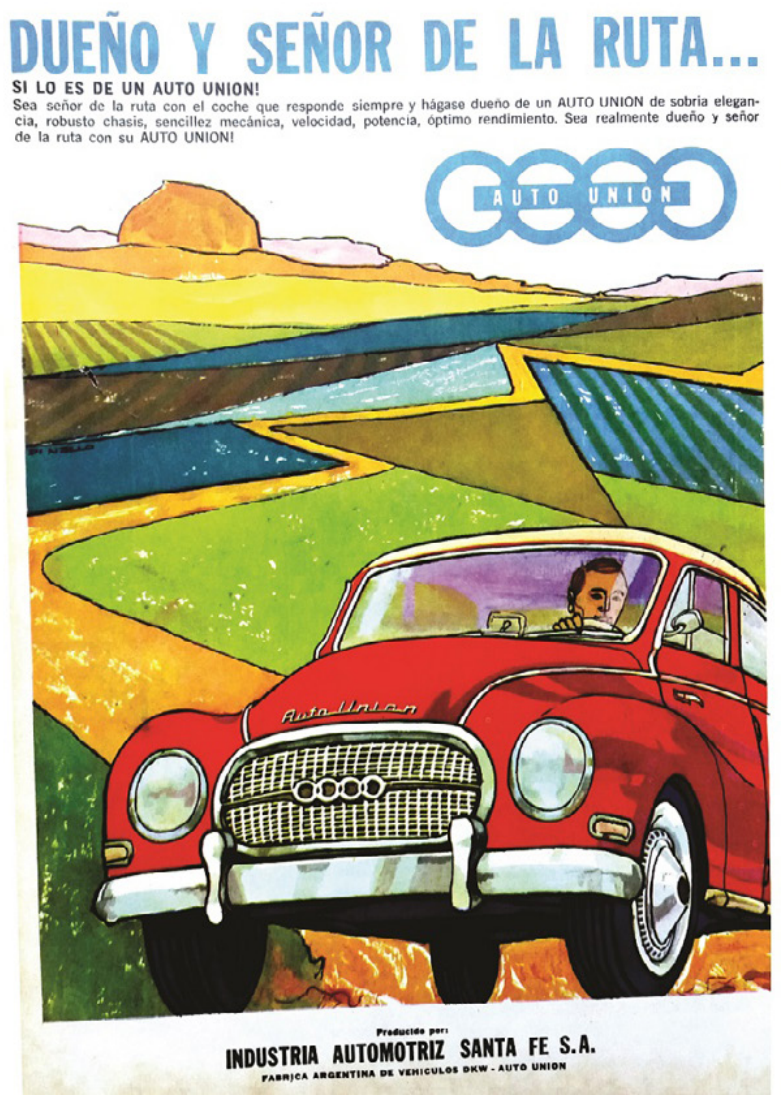

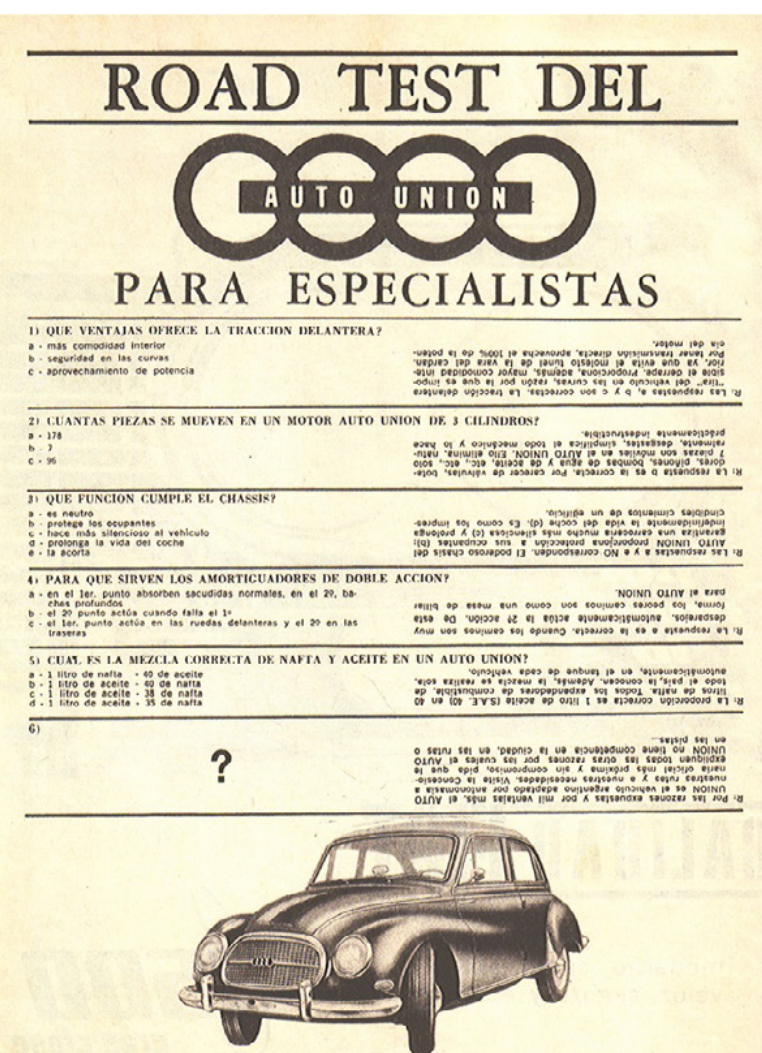

PRODUCIDO POR INDUSIRIA AUTOMOTRIL SANTA FE S.A. FABRICA ARGENTINA DE VEHICULOS DKW.AUTO UNION reactivación determinó una nueva etapa en la industria automotriz santafesina, focalizada en la fabricación de tractores, motores y camiones y, al mismo tiempo, signada por el periodo más sombrío del país.

\section{Segunda etapa del proyecto industrial automotriz: la Fiat Concord SA entre 1969 y 1981}

Vinculada desde sus inicios con el agro argentino, la empresa Fiat Concord se instala en la localidad de Sauce Viejo tras el traslado de su fábrica de tractores radicada previamente en el barrio Ferreyra de la ciudad de Córdoba. Más allá de la nueva marca automotriz y los cambios en la producción de unidades diferentes - de la fabricación de automóviles a la de tractores-, la Fiat no sólo mantuvo la estructura organizativa de IASFSA-DKW sino también incrementó la planta de trabajadores durante los primeros años de la década del 70. En el año 1973, la empresa amplía su complejo industrial para la fabricación de camiones con una capacidad productiva de 4.000 unidades al año y la incorporación de 600 trabajadores (El Litoral, 01/08/1974), alcanzando su máximo nivel de desarrollo hacia 1978 con la instalación de una tercera fábrica para la construcción de motores (Figura 6). Periódicos de la época revelan la jerarquía del Centro Industrial Fiat a nivel nacional:

En la actualidad, la actividad conjunta de estas tres fábricas, a las que se suma una modernísima planta de tratamiento térmico de partes mecánicas, ubican a esta realización de Fiat en la Argentina como una de las más importantes de América Latina, y como significativo factor de desarrollo local y regional al constituirse en fuente de trabajo directa y demandante de provisiones y servicios a centenares de otras empresas (El Litoral, o6/o8/1978).
Figura 5. Modelo Auto Unión 1000S fabricado en la planta industrial de Sauce Viejo. Izquierda: Publicidad. Fuente: Revista Parabrisas, $n^{\circ} 45$, Agosto de 1964. Derecha: Test de evaluación. Fuente: Revista Parabrisas, $n^{\circ}$ 44, Julio de 1964. 

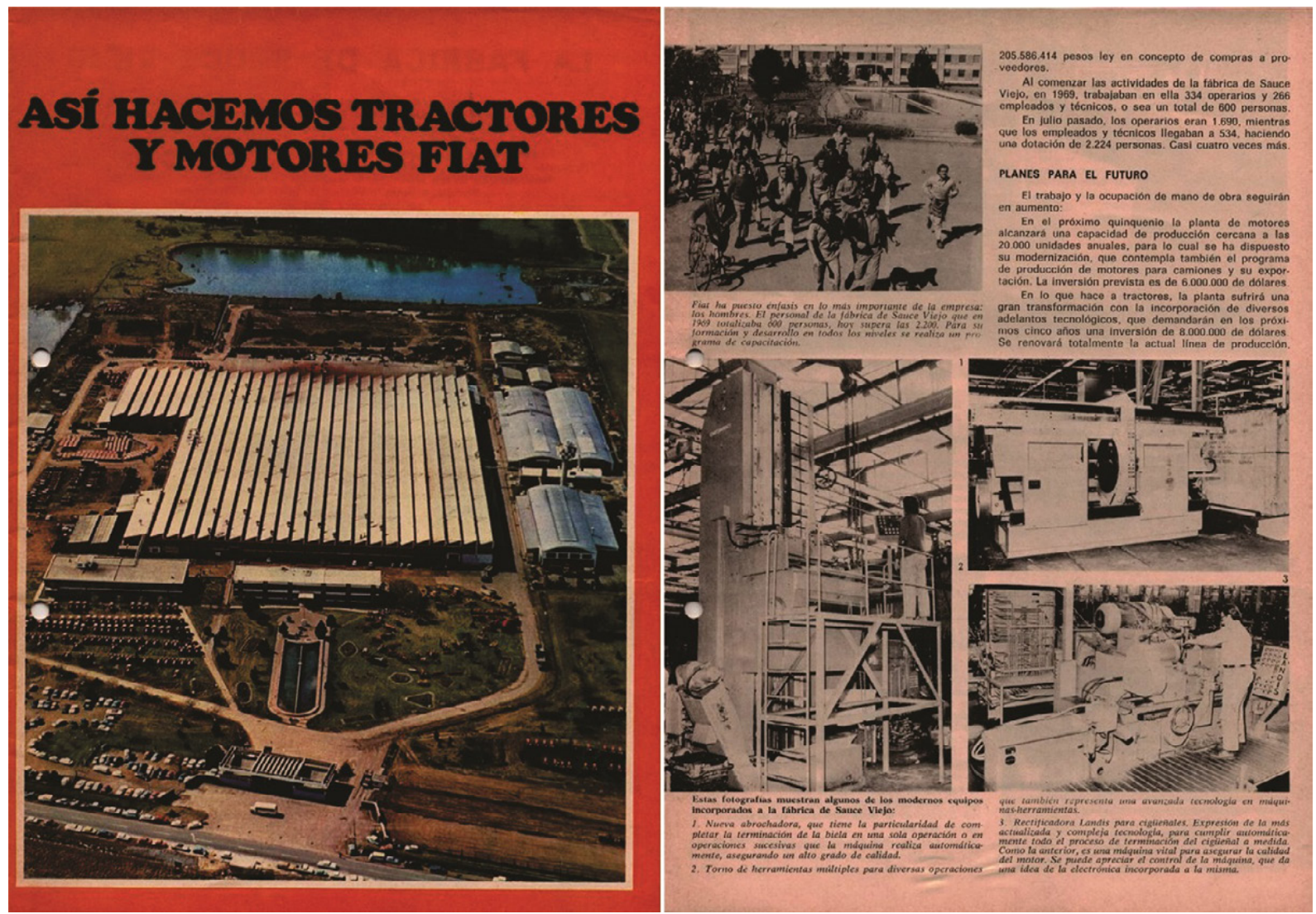

Un optimismo generalizado se refleja en el testimonio de ex trabajadores, vinculados a un progreso individual en el marco de un proyecto nacional desarrollista (Catedra eco ISP $n^{\circ} 8$ Alte G. Brown, 2011). Entre las valoraciones expresadas en dichos testimonios, se destaca la repercusión urbana del crecimiento de la empresa en la localidad de Santo Tomé. Sin comparar el caso local con el fenómeno de las Company Towns, una suma importante de empleados se radicó en las cercanías del complejo industrial incentivados por la posibilidad de adquirir terrenos o viviendas en áreas que experimentaban incipientes procesos de urbanización. Una posibilidad respaldada por salarios ventajosos, percibidos no sólo por los gerentes, jefes y supervisores, sino también por los mismos operarios que representaban un gran porcentaje del personal activo de la empresa. Las referencias indican que el sector aledaño a la intersección de las avenidas Luján y Ejército Argentino, trazas urbanas de las Rutas Nacionales 11 y 19 respectivamente, se urbanizó a partir de la llegada de trabajadores de la IASFSA-DKW pero, fundamentalmente, de la Fiat a lo largo de la década del 70. La cantidad de trabajadores empleados en esta última, 5.000 aproximadamente, superó ampliamente el número de activos de los años 60 . Este crecimiento estuvo acompañado de una actividad gremial centralizada en la Unión Obrera Metalúrgica -UOM- , y en políticas empresariales que, podría decirse, retomaron el modelo paternalista que la Fiat había implementado en Turín, Italia. Sin pretender una comparación entre ambas sedes, la creación de clubes deportivos, colonias de vacaciones, centros de salud, centros para jubilados, entre otros emprendimientos orientados a los empleados de la Fiat en Turín; resonó en territorio sauceño a partir de la creación del Club Fiat Sauce Viejo creado como centro recreativo familiar en terrenos aledaños al complejo industrial.

Aunque no todo derivó en progreso y desarrollo. Al tiempo que la Fiat se convertía en un polo productivo y tecnológico a nivel regional, y en una industria floreciente a nivel nacional, las sombras del período más oscuro de la historia argentina reciente también
Figura 6. Publicación oficial, año 1973. Portada: planta industrial Fiat Concord SA en Sauce Viejo. Fuente: Recuperado de http://pesadosargentinos.blogspot.com.ar/2015/og/ anexo-documentos-fiat.html 
se ciñeron sobre el complejo industrial de Sauce Viejo. Durante el proceso militar, 52 trabajadores de la Fiat en Argentina fueron asesinos o continúan desaparecidos, 35 de ellos pertenecían a las plantas de Ferreyra y 17 a las fábricas localizadas en el Gran Buenos Aires y Sauce Viejo y a las oficinas administrativas de Capital Federal (Basualdo et al., 2016:209-268). Durante la década del 70 las fábricas y complejos industriales se convirtieron en escenarios de conflicto, caracterizados por una intensa actividad gremial y el activismo de organizaciones políticas que legitimaban la lucha armada. El reclamo de los trabajadores derivó en huelgas, marchas, incluso en toma de fábricas, al tiempo que grupos armados asumieron estrategias más tenaces como el secuestro de funcionarios de empresas internacionales. En el caso de la Fiat tomó relevancia el secuestro y asesinato del Director General Oberdan Sallustro en 1972, a cargo del ERP -Ejército Revolucionario del Pueblo. En el testimonio de algunos ex trabajadores se reconoce una preocupación por diferenciar la dirigencia gremial de los grupos que pretendían sabotear a las grandes empresas (Catedra eco ISP n 8 Alte G. Brown, 2011). En el marco de estos conflictos, la intensidad de los reclamos se acrecentó hacia mediados de los 70 hasta el advenimiento de la dictadura, cuando la represión se convirtió en el modus operandi de la Junta Militar. En 1976, ocurrió gran parte de la desaparición de trabajadores, delegados gremiales y dirigentes sindicales de las distintas plantas Fiat (Basualdo et al., 2016:209-268). A medida que sucedían los asesinos y desapariciones, se hacía evidente el vínculo entre las fuerzas armadas y los directivos y personal jerárquico de la empresa, quienes eran conscientes de las violaciones a los derechos humanos cometidas contra sus trabajadores ${ }^{2}$. Sin embargo, la empresa se vio afectada luego de la reforma económica implementada por la política neoliberal a ultranza del Ministro de Economía Martínez de Hoz, marcando un punto de inflexión en el desarrollo de la Fiat en Argentina. En este contexto de desindustrialización, la Fiat abandona el complejo industrial de Sauce Viejo cerrando un periodo fundamental en la historia industrial santafesina.

\section{Un proyecto industrial inconcluso y una territorialidad latente}

Como se ha mencionado en la Introducción, sin intenciones de negar la fuerza vertebradora que poseen los ejes de conexión vehicular, se ha advertido que los actuales procesos de urbanización deberían ser comprendidos en base a aproximaciones que trasciendan lecturas causales y reduccionistas, ensayando un modo de abordaje que sea susceptible de concebir las complejas y dialécticas relaciones que suelen darse entre la traza y la mancha, entre los corredores viales y la expansión urbana. A partir de allí, y de los aportes conceptuales que nos han provisto una serie de estudios contemporáneos vinculados a la historia cultural, se ha ensayado una reconstrucción y una reflexión en torno a la territorialización de la actividad industrial sobre el corredor de expansión SF-ST-SV, a partir de la historia de la producción automotriz. Todo ello, con el objetivo de esbozar una primera mirada sobre la dimensión material y simbólica de la territorialidad industrial en los procesos de expansión de la ciudad de Santa Fe.

En el marco de las redefiniciones construidas en torno a los conceptos de espacio y territorio, se formuló la noción de territorialidades de la expansión con el objetivo de replantear metodológicamente el estudio de los corredores de expansión urbana. Superando visiones reduccionistas, en ciertos casos de sesgo formalista, y más precisamente aquellas perspectivas que analizan los territorios-zona desde dualismos dominantes, la idea de territorialidad supone la coexistencia de múltiples trayectorias (Massey, 2005) donde el territorio es comprendido en tanto red (Haesbaert, 2001), al tiempo que los espacios de la movilidad resultantes no pueden ser entendidos sino a partir de la integración del espacio percibido, concebido y vivido (Soja, 1999). Entre las redes dinámicas que impulsan la extensión de funciones urbanas, la territorialización de la actividad industrial ha sido
2. Esta conspiración registrada entre corporaciones multinacionales y militares ha sido explorada desde los estudios culturales. El trabajo de Karen Robert (2005) examina el vínculo entre la dictadura militar argentina y la empresa Ford a través del reconocimiento del Ford Falcon como expresión simbólica del terror. 

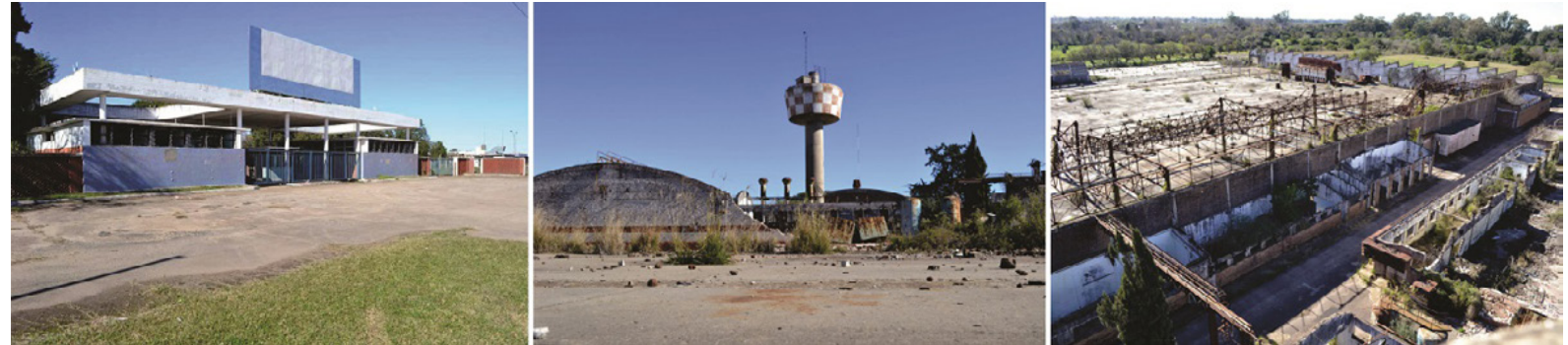

analizada a través de la producción automotriz y su repercusión en la caracterización del corredor SF-ST-SV, en tanto territorio atravesado por múltiples procesos que derivaron en diversas materializaciones urbanas y territoriales -institucionalización y concreción de la red caminera argentina y local, ampliación de la red de comunicaciones aéreas, políticas de Industrialización por Sustitución de Importaciones, impulso y crecimiento de la producción automotriz, intensificación de la actividad gremial, políticas neoliberales y desindustrialización-. Ahora bien, el análisis de esta territorialidad representa una aproximación parcial al crecimiento urbano de la ciudad de Santa Fe y su área de influencia, a ser complementado en futuras indagaciones con el estudio de aquellas otras territorialidades de la expansión, vinculadas fundamentalmente con la territorialidad residencial y de la vida cotidiana y la territorialidad del ocio y la recreación, entre otras. Territorialidades que presentan ciertas particularidades en función de su relación con los corredores viales de crecimiento, cuyas lógicas y dinámicas urbanas resultan ajenas a los procesos de urbanización en el ámbito de la ciudad central o compacta.

La noción de territorialidades latentes, sugerida en el título de esta presentación, oficia de nexo entre la territorialización de la actividad industrial en el corredor SF-ST-SV y la perspectiva contemporánea centrada en el nuevo paradigma de los estudios de la movilidad. Entendido el desplazamiento más allá del simple propósito de alcanzar un destino y, por lo tanto, como una práctica social creadora de espacio urbano, la materialización de los procesos anteriormente mencionados vinculados a la producción automotriz son resignificados en función de la cotidianeidad emergente en el corredor. Cotidianeidad que, en alusión al "espacio cotidiano" de Crawford (2014), convive e interacciona con un pasado reciente de desarrollo y progreso. Sin dudas, el ciclo abordado entre la instalación de la Auto Unión DKW y la Fiat Concord SA representan un hito central en la historia del desarrollismo local, un periodo que hoy revive en las movilidades cada vez más cotidianas sobre el corredor de la RN11 y los desplazamientos que a diario atraviesan las ruinas de un pasado no muy lejano (Figura 7). Movilidades creadores de espacio, de lugares, de memoria. Y quizás esta memoria no pasó del todo inadvertida en los últimos 36 años. La movilidad familiar y recreativa que generó el Club del Personal de Fiat Sauce Viejo en los años 70, no sucumbió al deceso de la empresa, siendo la única instalación aún en funcionamiento del ciclo de la industria automotriz en Santa Fe (Figura 8).
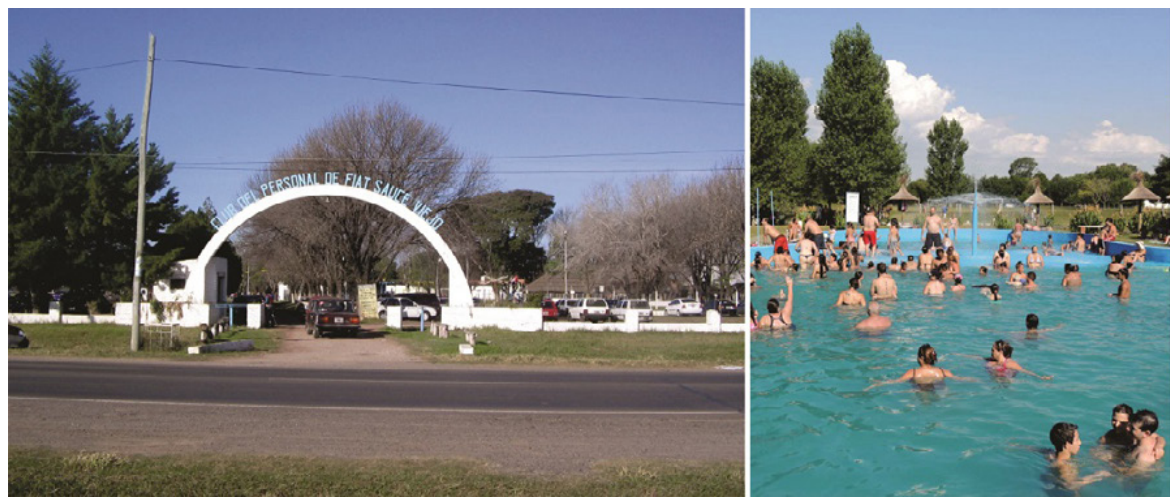

Figura 7: Imágenes actuales del complejo industrial en Sauce Viejo, en desuso desde 1981. Fuente: Publicación digital Voces del Salado, 2014. Recuperado de http://voces.ellitoral.com/2014/06/30/ los-huesos-de-la-ex-fiat-blanqueanen-un-predio-que-quiere-renacer
Figura 8: imágenes del funcionamiento actual del Club del Personal de Fiat Sauce Viejo. Fuente: Recuperado de la red social de la dicha Institución. https://es-la. facebook.com/Club-Ex-personalFiat-Sauce-Viejo-674400092605375/

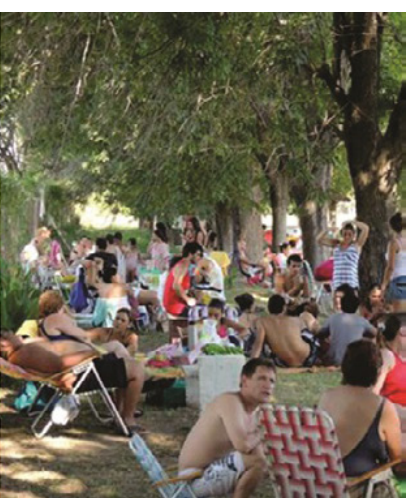




\section{Q Bibliografía}

» BASUALDO, Victoria et al. (2016) Parte IV. Zona centro argentino. En Basualdo, V. [et al.]. Responsabilidad empresarial en delitos de lesa humanidad: represión a trabajadores durante el terrorismo de Estado.Posadas, Editorial Universitaria de la Universidad Nacional de Misiones, p. 209-268.

» BALLENT, Anahí (2005) Kilómetro Cero: La construcción del universo simbólico del camino en la Argentina de los años treinta. Boletín del Instituto de Historia Argentina y Americana "Dr. Emilio Ravignani", nº 27, Buenos Aires, Universidad de Buenos Aires, p. 107-137.

» BLANCO, Jorge (2006) De la noción de impacto a la de procesos asociados. Reflexiones a partir de la relación autopistas-urbanización en la Región Metropolitana de Buenos Aires. Mundo Urbano, $n^{\circ}$ 28, Buenos Aires, Universidad Nacional de Quilmes, <http://www.mundourbano.unq.edu.ar/index.php/ano2006/26-numero-28/188-2-de-la-nocion-de-impacto-a-la-de-procesos-asociados>

" BLANCO, Jorge (2016) Urbanización y movilidad: contradicciones bajo el modelo automóvil - intensivo. Transporte y Territorio, $n^{\circ} 16$, Buenos Aires, Universidad de Buenos Aires, p.96-113, <http://revistascientificas.filo.uba.ar/ index.php/rtt/article/view/2852/2475>

" CASTRO, Hortencia, LOIS, Carla y ZUSMAN, Perla (2007) Viajes y geografías. Buenos Aires: Prometeo Libros.

" CRAWFORD, Margaret (2014) Difuminando los límites: espacio público y vida privada. En Á. Martín Ramos (edit.).La calle moderna en 30 autores contemporáneos. Barcelona, Ediciones UPC, p. 123-130.

» DIRECCIÓN PROVINCIAL DE VIALIDAD (1988) Evolución histórica de la vialidad provincial. Santa Fe: DPV.

» GUTIERREZ, Andrea (2012) ¿Qué es la movilidad? Elementos para (re)construir las definiciones básicas del campo del transporte. Bitácora Urbano Territorial, vol.2, n²1, Bogotá, Universidad Nacional de Colombia, p. 61-74.

" HAESBAERT, Rogério (2011) El mito de la desterritorialización. Del "fin de los territorios" a la multiterritorialidad. México: Siglo XXI.

» MASSEY, Doreen (2005) For Space. Londres: SAGE Publications Ltd.

» MIRALLES-GUASCH, Carme (2002) Ciudad y transporte. El binomio imperfecto. Barcelona, Ariel.

» MORAGLIO, Massimo (2007) Betweenindustry and tourism. TheTurin-Savona motorway, 1956-2001.Thejournal of TransportHistory, vol. 28, n1, Manchester, Manchester Press, p.93-110.

»NOVARO, Marcos (2010) Frondizi, entre la proscripción y la integración. En Novaro, M. Historia de la Argentina 1955-2010. Buenos Aires, Siglo Veintiuno Editores, p. 39-63.

»OFFNER, Jean-Marc (1993) Les «effetsstructurants» du transport: mythepolitique, mystificationscientifique. L'Espacegéographique vol. 22, $\mathrm{n}^{\circ} 3$, p. 233-242.

» ROBERT, Karen (2005) The Falcon Remembered. NACLA Report on the Americas,vol.39, n³, New York, New York University, p.12-15. 
» SHELLER, Mimi y URRY, John (2006) The new mobilitiesparadigm. Enviroment and Planning A, vol.38, nº2, Canadá, University of British Columbia, p. 207-226.

"SOJA, Edward (1999) Thirdspace: Expanding the Scope of the Geographical Imagination. En D.Massey, J. Allen, \& P. Sarre (edits.). Human Geography Today. Londres, PolityPress, p. 260-278.

» VICENTIN, Enzo (2013) La empresa automotriz IASFSA en Santa Fe. Características de una experiencia en los márgenes (1959-1969). Avances del Cesor, $\mathrm{n}^{\circ}{ }_{10}$, Rosario, Universidad Nacional de Rosario, p. 9-33.

\section{Diarios y revistas}

» (1928) La pavimentación de caminos. En El Orden, 11 de Octubre, p. 8.

» (1935) Un aeródromo es de necesidad en Santa Fe. En El Litoral, 14 de Abril, p. 2.

» (1949) Hay que dotar a nuestra capital de un cómodo aeródromo. En El Orden, 12 de Octubre, p. 8.

» (1950) Trasladaran las instalaciones del Aero Club Santa Fe a la zona de Sauce Viejo. En El Orden, 29 de Noviembre, p. 8.

" (1955) Quedó inaugurado esta mañana el servicio de Aerolíneas Argentinas para nuestra capital. En El Litoral, o9 de Diciembre, p. 3

» (1960) Llegó al puerto el primer cargamento destinado a Industrias Automotriz Sta. Fe D.K.W. Auto Unión. En El Litoral, 25 de Enero, p. 5.

» (1960) Esta mañana fueron presentadas las primeras unidades Auto Unión montadas en esta ciudad. En El Litoral, 03 de Febrero, p. 5.

"(1960) En Sauce Viejo colocóse la piedra fundamental para la fábrica de Industria Automotriz Santa Fe. En El Litoral, 22 de Marzo, p. 4.

» (1960) Con ritmo acelerado se trabaja construyendo la planta de la ToolResearch frente a la ruta 11. En El Litoral, o8 de Octubre, p. 5.

» (1961) De Alemania a Sauce Viejo, vía Santa Fe. En El Litoral, o2 de Septiembre, p. 6.

" (1964) Road Test del Auto Unión para especialistas. En Revista Parabrisas, n 44.

" (1964) Publicidad Dueño y señor de la ruta. En Revista Parabrisas, n 45.

" (1969) La situación de D.K.W. En El Litoral, os de Abril, p. 4.

» (1974) Fiat construye ya camiones en Santa Fe. En El Litoral, o1 de Agosto, p. 5.

» (1978) Sauce Viejo: un centro industrial Fiat con potencia. En El Litoral, o6 de Agosto, p. 8-9.

" (2014) Los "huesos" de la ex Fiat blanquean en un predio que quiere renacer. En Voces del Salado, 30 de Junio. Recuperado de http://voces.ellitoral.com/2014/06/30/ los-huesos-de-la-ex-fiat-blanquean-en-un-predio-que-quiere-renacer/

\section{Video}

» CATEDRA ECO DEL ISP № 8 ALMIRANTE GUILLERMO BROWN. PROFESORADO DE HISTORIA. 2011. Fiat Sauce viejo: notas para una historia ausente. https://www.youtube.com/watch?v=7Set/MCpWFo 


\section{Fuentes de internet}

" "Fábrica Auto Unión en Argentina 1960 (parte 1)" (n.d.). Recuperado el 17/V/2017 desde https://www.flickr.com/photos/autounion1965/ albums/72157606595632693

" "Fábrica Auto Unión en Argentina (parte 2)" (n.d.). Recuperado el 07/X/2017 desde https://www.flickr.com/photos/autounion1965part2/ albums/72157629278662316

" "Pesados argentinos. Tractores, cosechadoras, maquinaria vial, grúas y montacargas fabricados en Argentina desde 1905" (n.d). Recuperado el 15/ $\mathrm{Vl} / 2017$ desde http://pesadosargentinos.blogspot.com.ar/2015/og/anexodocumentos-fiat.html

" "Club Expersonal FiatSauce Viejo"(n.d.). Recuperado el 9/VI/2017 desde https:// es-la.facebook.com/Club-Ex-personal-Fiat-Sauce-Viejo-674400092605375/

\section{Estefanía Szupiany / eszupiany@gmail.com}

Arquitecta por la Universidad Nacional del Litoral y Doctoranda en Arquitectura de la Universidad Nacional de Rosario. Actualmente becaria doctoral CONICET y miembro del Instituto de Humanidades y Ciencias Sociales del Litoral IHUCSO UNL-CONICET. Docente en la Facultad de Arquitectura, Diseño y Urbanismo de la UNL e Investigadora en el Grupo de Trabajo CLACSO 2016-2019: Desarrollo, espacio y capitalismo global. 